\title{
Medical audit and formulary management: a policy for rational use of thrombolytic drugs
}

\author{
D.J.R. Morgan, Carol A. Sutters* and Sara Pugh ${ }^{1 * *}$
}

Department of Clinical Pharmacology and Therapeutics and ' Academic Department of Cardiovascular
Medicine, Charing Cross and Westminster Medical School, 17 Page Street, London SWIP 2AP, UK

Summary: In this article we report on the development, introduction, and maintenance of a policy to promote rational use of thrombolytic drugs by hospital doctors. The work was undertaken within the framework of the voluntarily operated Riverside East drugs guide (formulary) management system (FMS). The policy was introduced in October 1988 and revised in November 1989 to coincide with the launch of the new, expensive thrombolytic drugs, alteplase (rt-PA, Actilyse) in 1988 and antistreplase (APSAC, Eminase) in 1989. Streptokinase was recommended as the first-line drug for patients who had not received it within the last 6 months. The policy was communicated to all staff in meetings and a drugs guide bulletin and reinforced by ward pharmacists.

Results over a 15 month period show voluntary compliance by prescribers with the recommended policy. One hundred and seventy-four patients (22\% cardiac admissions) presented with acute myocardial infarction. Of these $43(25 \%)$ received streptokinase, the first-line recommended drug, 7 received alteplase and none received anistreplase. The savings in drug expenditure from using streptokinase rather than alteplase or anistreplase for the 15-month period of investigation were over $\mathbf{2 7 , 0 0 0}$. This work represents an example of the effectiveness of the Riverside East FMS model in influencing prescribing behaviour.

\section{Introduction}

Thrombolytic therapy is a proven method of reducing mortality after acute myocardial infarction (AMI). At present there seems to be no major difference in mortality reduction between the three currently available thrombolytic agents although results of further trials are awaited. However, there is a very major difference in cost between these three agents.

In June and July 1988, alteplase had been used free of charge for patients who entered a clinical trial study (SHAPE). During this time considerable local interest in the use of the drug had been generated. The pharmaceutical manufacturers of alteplase (rt-PA, Actilyse) undertook a series of discussions with district pharmacists, general managers and many other staff, to increase awareness of the launch of alteplase and the considerable potential cost implications for each district. They announced that they planned to sell the drug at a cost of approximately $£ 1000$ for a single patient's treatment. Understandably, this aroused much

\footnotetext{
*Present address: Glaxo Pharmaceuticals (formerly Principal Pharmacist, Riverside East Drugs Guide).

**Present address: Sunderland District General Hospital, Sunderland, UK.

Correspondence: D.J.R. Morgan, M.R.C.P.

Accepted: 4 October 1990
}

concern because the potential for expenditure on alteplase could have instantly risen from zero to approximately $£ 200,000$ based on the estimated number of AMI cases that would present in Riverside East in the following year. So in September 1988 the Riverside East Drugs Committee decided to examine local prescribing practice concerning the effective use of thrombolytic therapy for the management of AMI.

The voluntary mode of operation of the Riverside East drugs guide (formulary) has previously been reported ${ }^{1,2}$ together with the formulary management system (FMS) model for influencing prescribing behaviour. ${ }^{3}$ In this investigation we posed the hypothesis that the Riverside East FMS model could be used to education clinicans about a policy to promote rational use of thrombolytic drugs and thereby influence prescribing behaviour.

\section{Methods}

In 1988 Riverside East Acute Unit comprised five hospitals including St. Stephen's and Westminster teaching hospitals. At this time the formulary covered drug usage for $\mathbf{4 0 0}$ hospital beds by over 400 clinicians. Acute cardiac emergencies were admitted until March 1989 into either the cardiac care unit (CCU) at Westminster Hospital or the 
intensive care unit (ITU) at Westminster or St. Stephen's Hospitals. After this date one of our hospitals, St. Stephen's Hospital, closed and only one CCU and one ITU department remained.

The Drugs Committee set up a task force group in September 1988 to examine the concept of thrombolytic therapy. The group aimed to undertake audit of current practice, and make recommendations to clinicians and general managers about future thrombolytic clinical management policy and its cost implications.

The task force group comprised two consultants and a senior registrar from cardiology, the professor of clinical pharmacology, a general medical consultant, and the formulary principal pharmacist. They considered current thrombolytic patient management and undertook a drug utilization review of thrombolytic drugs. This included a review of published literature and consideration of efficacy, toxicity, workload and cost. They also discussed liaison between CCU and ITU clinical staff and arrangements for acceptance of AMI cases from general practitioners. Formal recommendations were agreed based upon the ISIS-2, ${ }^{4}$ AIMS, ${ }^{5}$ and ASSET ${ }^{6}$ trials. Each member of the task force group was allocated duties to assist completion, effective communication and subsequent operation of the policy. The group met again in September 1989, shortly after the marketing of a second, expensive, thrombolytic drug, anistreplase (APSAC/Eminase) with further cost implication if widely prescribed.

Meetings were held in pharmacy, CCU and ITU to inform staff of the policy and make them aware of their obligations for effective patient management. The policy educated doctors how to use the drugs appropriately (Figure 1). Arrangements were made for storage of drugs and a pump for streptokinase infusion in readiness in the relevant departments. Records of the use of thrombolytic drugs for patients with AMI were kept in CCU and ITU departments in order to monitor the effectiveness of our policy. The cardiology senior registrar also held a meeting with junior medical staff involved in the admission of patients with AMI to explain the background and operation of the local policy and to provide professional support. A drugs guide bulletin on management of thrombolysis was first produced in 1988 to communicate the policy. Bulletins were distributed to all medical, nursing and pharmacy staff.

Drugs were selected according to proven efficacy, relative toxicity and cost, as agreed by local specialist opinion. In 1988 when alteplase was first licensed, the local policy recommended streptokinase as the first-line drug of choice. Alteplase was available for patients who had received streptokinase within the last 6 months, because of the risk of antigenicity. Following licensing of anis- treplase in September 1989 it was felt appropriate to review the policy. Anistreplase, a pro-drug of streptokinase, still retained allergic potential, therefore alteplase remained the treatment of choice where streptokinase was given in the past 6 months. In the revised policy streptokinase was still considered the first-line choice. Anistreplase and alteplase were recommended as second-line drugs. Anistreplase was available for cases where there was a delay in setting up the streptokinase infusion because of its ease of administration, and alteplase was recommended where either streptokinase or anistreplase had been given in the last 6 months. Figure 2 shows part of the 1989 bulletin which briefly compares aspects of the three drugs streptokinase, alteplase and anistreplase that were considered by members of the task force group. The bulletins also provided guidelines for the management of AMI. The policy was reinforced by ward pharmacists.

\section{Results}

In the 6-month period, January to June 1988, before the SHAPE study no alteplase had been given to patients presenting with AMI. During the study period September 1988 - November 1989 174 patients with AMI (22\% cardiac admissions. were admitted. Forty-three patients receive thrombolytic therapy $(25 \%)$ of which 36 received streptokinase and 7 received alteplase (Figure 3). No patient received anistreplase. This was despite the availability of alteplase in 1988 and both alteplase and anistreplase from June 1989. If alteplase had been used in all cases where streptokinase was given the expenditure on alteplase would have exceeded $£ 30,000$ based on hospital discounted prices (which were considerably lower than the original $£ 1000$ price quoted). The estimated saving resulting from the use of streptokinase instead of alteplase was over $£ 27,000$ for the 15 -month period. In November and December 1988 and January 1989 there was a small amount of short-dated alteplase available and pharmacy advised that it could be used if requested. Obviously the drug costs in relation to total in-patient costs would need to be considered as part of a thorough cost-benefit analysis investigation however this information was not available in this study.

\section{Discussion and conclusions}

These results show that our policy of recommending streptokinase as first-choice thrombolytic therapy for the management of AMI was supported by the clinicians during this study period. Alteplase 


\section{RECOMMENDED PROTOCOL FOR INTRAVENOUS STREPTO- KINASE IN ACUTE MYOCARDIAL INFARCTION}

\section{Patients}

Not more than 70 years old

Severe chest pain unrelieved by nitrates

ST-segment elevation of at least $2 \mathrm{~mm}$

Within 4 hours of the onset of pain

\section{Exclusions}

Cardiogenic shock, cardiopulmonary resuscitation, history of CVA, GI-bleed in last 3 months, major surgery in last 3 months, severe hypertension, major hepatic/renal disease, bleeding diathesis, oral anticoagulants.

\section{Investigations}

Routine bloods, group and save, clotting screen (PT*, APTT, TT), CXR and ECG. Daily cardiac enzymes for 3 days. Daily APTT while heparin infusion in progress.

\section{Drugs}

Peripheral or CVP line for access.

Hydrocortisone sodium succinate initially $200 \mathrm{mg}$ IV.

Streptokinase $(900,000-1,500,000$ i.u.) IV in $100 \mathrm{ml} 5 \%$ Glucose over 30 minutes.

Then heparin 5000 i.u. IV and start continuous infusion at 1000 i.u./hour for 72 hours adjusting dose to achieve a PTT of 2-4 $\times$ normal. Please refer to IV Policy Booklet. Start oral aspirin $75 \mathrm{mg} /$ day.

\section{ECG}

$\begin{array}{lll}\text { Record i) } & \text { prior to commencing } \\ & \text { ii) } & \text { post-streptokinase (immediately) } \\ & \text { iii) } 1 \text { hour post-streptokinase therapy }\end{array}$

Exceptionally if after 5 or more days following the administration of streptokinase further thrombolytic therapy is required, then rt-PA would be indicated. If this is thought to be required then it should be discussed with Dr P. Collins, Senior Registrar, Cardiology WH.

"Note PT $=$ Prothrombin time, APTT = Activated partial thromboplastin time, $\Pi=$ Thrombin time

Figure 1 Part of the 1988 Thrombolytic Policy Bulletin which gives patient inclusion and exclusion criteria.

was used very rarely. In two patients it was used according to the recommended policy and in five patients it was administered to utilize stock of short-dated alteplase. Anistreplase was not prescribed. In a future study we would plan to identify cases where patients received streptokinase in whom anistreplase would have been more appropriate. We were surprised that streptokinase was not used more often. The use of thrombolytic therapy in AMI has been generally observed to be less than $30 \%$ in some studies in acute hospitals. ${ }^{7}$ This might indicate a need for further reinforcement of our policy.

This study has demonstrated that prescribing of thrombolytic drugs and management of AMI can be influenced by a programme of education by peers and reinforcement by clinicians and pharmacists. It was not the intention of the study to assess total cost-benefit analysis, but to simply measure implementation and voluntary compliance of a policy agreed by local specialists. Full clinical audit would include assessment of patient outcome which was beyond the scope of our current policy. It is important to emphasize that the policy was advisory and clinicians had every opportunity to use the second-line drugs alteplase or anistreplase if they preferred.

Attempts to alter prescribing behaviour should embrace the full cycle of audit. ${ }^{8}$ The high voluntary compliance with the recommended policy suggests that strong and convincing arguments were proposed in the local policy which encouraged clin- 


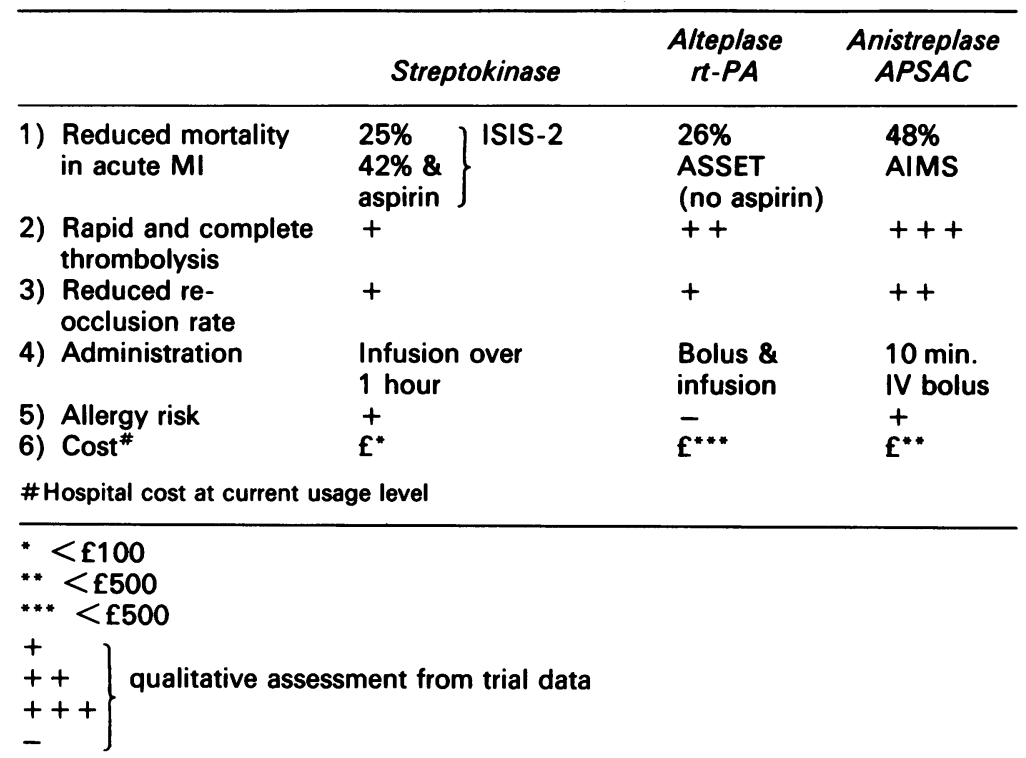

Figure 2 Part of the 1989 Thrombolytic Policy Bulletin which compares certain aspects of the three recommended drugs.

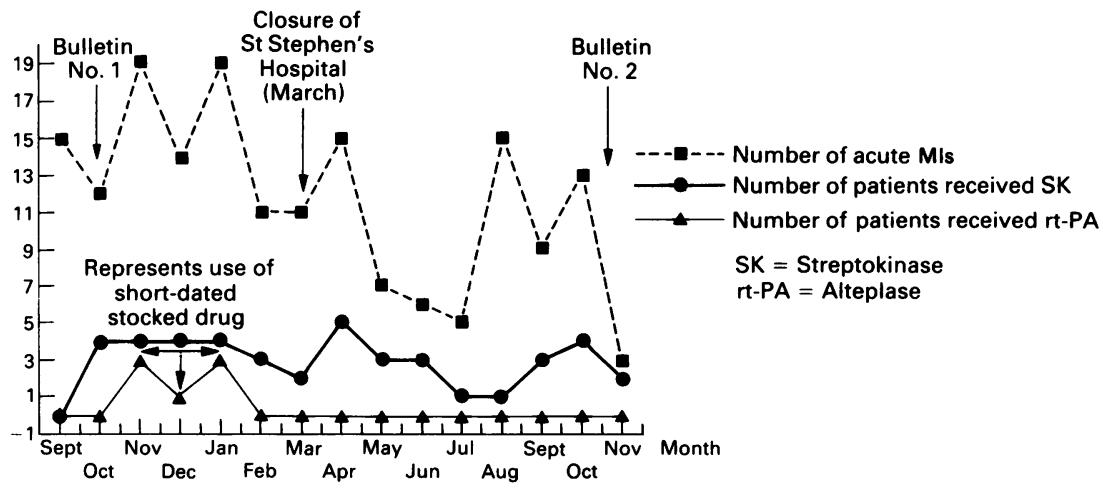

$\begin{array}{llllllllllllllll}60 & 48 & 53 & 41 & 62 & 52 & 53 & 60 & 49 & 53 & 62 & 55 & 53 & 49 & 56 & \text { Total number acute cardiac admissions }\end{array}$

Figure 3 Use of thrombolytic drugs streptokinase and alteplase (rt-PA) for patients presenting with acute myocardial infarction (MI) in Riverside East Hospitals, September 1988-November 1989. The acute myocardial infarction and acute cardiac case workload figures are also presented.

icians to comply. Such a system needs the authority of local respected senior specialists. ${ }^{8}$ The importance of medical colleagues must be emphasized. ${ }^{9,10}$ Colleagues are the most important source of information at the evaluation stage of a new drug and early adoption of a new drug is associated with integration of the three social networks of interpersonal relations based on communications, advice, discussion and friendship networks. ${ }^{9}$ We were encouraged by the trust shown by colleagues, especially consultants of accident and emergency departments and intensive therapy units in their willingness to accept readily the advice of fellow specialists and to recommend this to their staff. The meetings that were organized in the various departments gave staff in these areas an opportunity to be active participants in the learning process, a method of postgraduate education that is likely to 
produce change in clinical practice. ${ }^{11}$ Participation of clinicians in such meetings also generates ownership and sympathy with objectives which encourages voluntary compliance with local policies.

Bulletins provide the ideal opportunity for active ward pharmacy intervention and reinforcement of policies but they need to be reinforced by other change influences. ${ }^{12}$ Consultations by pharmacists at ward level, especially with inexperienced clinicians, provide a unique opportunity to strengthen confidence, develop skills and produce long-term attitudinal change in clinicians. ${ }^{13}$ In the case of thrombolytic therapy where drugs are administered within 6 hours of onset of symptoms, there is unlikely to be an opportunity for ward pharmacist intervention prior to administration of the drug.

The timing of promotion of our local policy was crucial. We avoided considerable potential confusion by the prompt release of our policy, at or directly after the market launch of the new throm- bolytic drugs. Anticipation of these events was possible because we had developed clinical experience and knowledge of the new drugs during clinical trial investigation.

We would recommend the use of this voluntary model for improving patient management in other therapeutic areas in hospital practice and its extension with appropriate reinforcement to general practice medicine.

\section{Acknowledgements}

We wish to thank the many clinicians and pharmacists in Riverside East who have willingly co-operated and supported the thrombolytic policy. We also wish to thank Professor A.F. Lant and Professor M. Noble for their encouragement and leadership and Dr P. Collins, former Senior Registrar in Cardiology at Westminster Hospital, for his assistance with preparation of the original policy.

\section{References}

1. Sutters, C.A. Peer group review of drugs and the way forward. Pharm J 1989, 244: 246-248.

2. Baker, J.A., Lant, A.F. \& Sutters, C.A. Seventeen years' experience of a voluntarily based drug rationalisation programme in hospital. Br Med J 1988, 297: 465-469.

3. Sutters, C.A. The management of a hospital formulary. J Clin Pharm Therap 1990, 15: 59-77.

4. ISIS-2 Collaborative Group. Randomised trial of intravenous streptokinase, oral aspirin, both, or neither among 17,187 cases of suspected acute myocardial infarction. Lancet 1988, ii: $349-360$.

5. AIMS Trial Study Group. Effect of intravenous APSAC on mortality after acute myocardial infarction: preliminary report of a placebo-controlled clinical trial. Lancet 1988, ii: 545-549.

6. Wilcox, R.G., Olsson, C.G., Skene, A.M. et al. Trial of tissue plasminogen activator for mortality reduction in acute myocardial infarction, Anglo-Scandinavian Study of Early Thrombolytics. (ASSET). Lancet 1988, ii: 525-533.

7. Burrell, C.J., Skehan, J.D., Cowley, M.L. et al. Districts' use of thrombolytic agents. Br Med J 1990, 300: 237-238.

8. Mitchell, M.W. \& Fowkes, F.G.R. Audit reviewed: does feedback on performance change clinical behaviour? J $R$ Coll Physicians 1985, 19: 251-254.

9. Miller, R.R. Prescribing habits of physicians: a review of studies on prescribing of drugs (parts 1-3). Drug Intell Clin Pharm 1987, 7: 492-500.

10. Coleman, J., Menzel, H. \& Katz, E. Social processes in physicians adoption of a new drug. J Chron Dis 1959, 9: 1 .

11. Herxheimer, A. \& Twycross, R. Continuing education in therapeutics; aids to discussions on prescribing. $\mathrm{Br}$ Med J 1976, i: $1198-1199$.

12. Plumridge, R.J. Intervention strategies aimed at modifying prescribing behaviour. Aust J Pharm 1984; 14: 93-100.

13. Plumridge, R.J. \& McGehie, D.B. Assuring rational antibiotic use: the impact of a joint microbiology - pharmacy surveillance programme. Aust Health Rev 1984, 7: 4. 